\title{
AMBOID REAR AXEL APPLIED AT COMPACTOR TRUCKS 6X2 WITH PUSHER SYSTEM
}

\author{
${ }^{1}$ MAN Latin America \\ ${ }^{2}$ MAN Latin America \\ ${ }^{3}$ MAN Latin America \\ ${ }^{4}$ MAN Latin America \\ ${ }^{5}$ MAN Latin America \\ ${ }^{6}$ MAN Latin America \\ ${ }^{7}$ MAN Latin America
}

Amaral, Sergio Roberto ${ }^{1}$, Tavares, Robson Pereira ${ }^{2}$, Junior, Alvaro Yukio Kubo ${ }^{3}$, Servilheira, Lucas Germano Gonzaga ${ }^{4}$, Reeve, Breno Martins Everard ${ }^{5}$, Souza, André Cristiano $^{6}$ and Cordeiro Junior, Luiz Carlos ${ }^{7}$

sergio.amaral@volkswagen.com.br, robson.tavares@volkswagen.com.br, alvaro.kubo@volkswagen.com.br, lucas.servilheira@volkswagen.com.br, breno.reeve@volkswagen.com.br, andre.souza2@volkswagen.com.br and

luiz.cordeiro@volkswagen.com.br.

\begin{abstract}
The compactors trucks $6 \mathrm{X} 2$ use hypoid rear axle with pusher system causes the application. The suspension characteristics for pusher system with hypoid axles increase the universal joint angle at transmission side and at rear axle side. The drive shaft geometry is approved for the application however the angles of universal joint are at border line for torsional and inertial acceleration according to supplier application sheet approval. Evaluation on the test vehicles at $12 \%$ and $20 \%$ uphill ramp were confirmed a judder vibration at $1^{\text {st }}$ gear between 1600 and $1800 \mathrm{rpm}$ during start/stop test and between 65 and $85 \mathrm{~km} / \mathrm{h}$. To solve this vibration was requested to rear axle supplier to send 3D model to evaluate new amboid rear axle design regarding to accelerations analysis. After assembly at Digital Mock up (DMU) was verified the improvement regarding universal joint angle reduction and also the possibility to reduce some others components and have a cost reduction also. The new application sheet shows a low acceleration (torsional and inertial), increase the B 10 estimated life and increases the critical speed for the drive shaft also. The new concept was assembled and tested in parallel of the current one and we could confirm the judder vibration was eliminated at $12 \%$ and $20 \%$ uphill ramp between 1600 and $1800 \mathrm{rpm}$ and between 65 and $85 \mathrm{~km} / \mathrm{h}$. the patent regarding an amboid rear axle application at compactors trucks $6 \mathrm{X} 2$ pusher was requested.
\end{abstract}




\section{INTRODUCTION}

The current compactors trucks $6 \mathrm{X} 2$ with pusher system are developed with a hypoid rear axle. The suspension and drive shaft geometry combination makes the angle increase to the border line for supplier application approval. The engineering tests found judder vibration during the tests at uphill ramp (12 and 20\%) and between 65 and 85 $\mathrm{km} / \mathrm{h}$. The vibrations conditions were always approved because it was not possible to improve the universal joint angle for transmission side and rear axle side to get best geometry condition. It is a result to use the pusher system for this application. Basically all truck makers have the same condition because all use the same or similar pusher system.

\section{CURRENT SITUATION}

Basically truck makers follow the layout bellow including special mancal support to absorb angles upper than $5^{\circ}$ at universal joint.

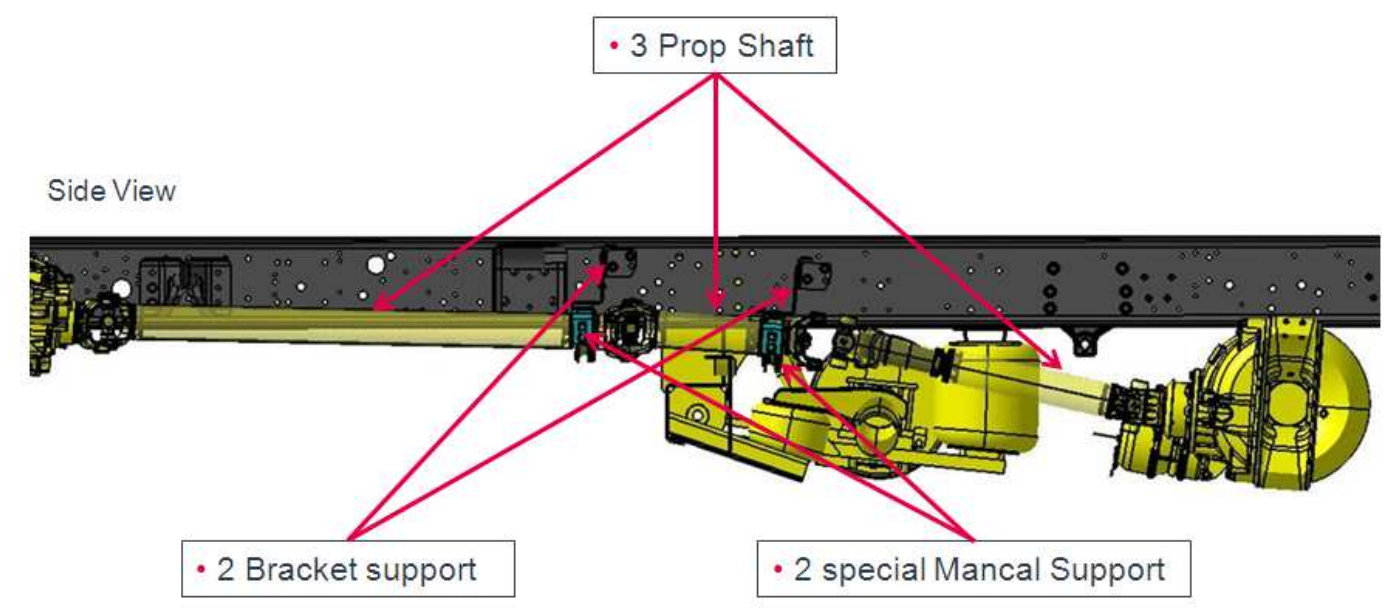

Picture 1. Current compactors $6 X 2$ pusher design.

\section{AMBOID REAR AXLE}

Amboid gears also employ an offset pinion to ring gear mounting arrangement, but the pinion gear is mounted above the ring gear's centerline.

The ambiod rear axles normally are used at $6 \mathrm{X} 4$ vehicles. The characteristics of load capacity are the same of currently hypoid assembled at compactors $6 \mathrm{X} 2$ trucks.
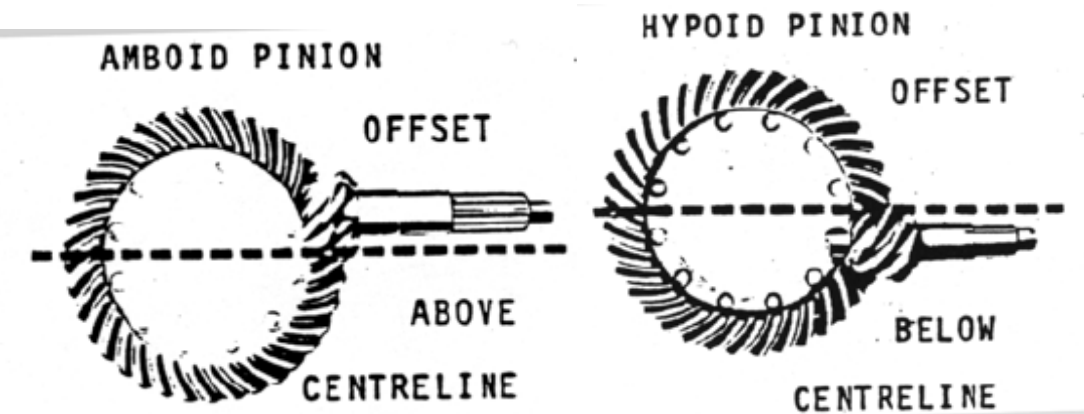

Picture 2. Amboid and hypoid gears characteristics (i.e. [2]). 
Both axle configurations have good surface engagement of the gear tooth.

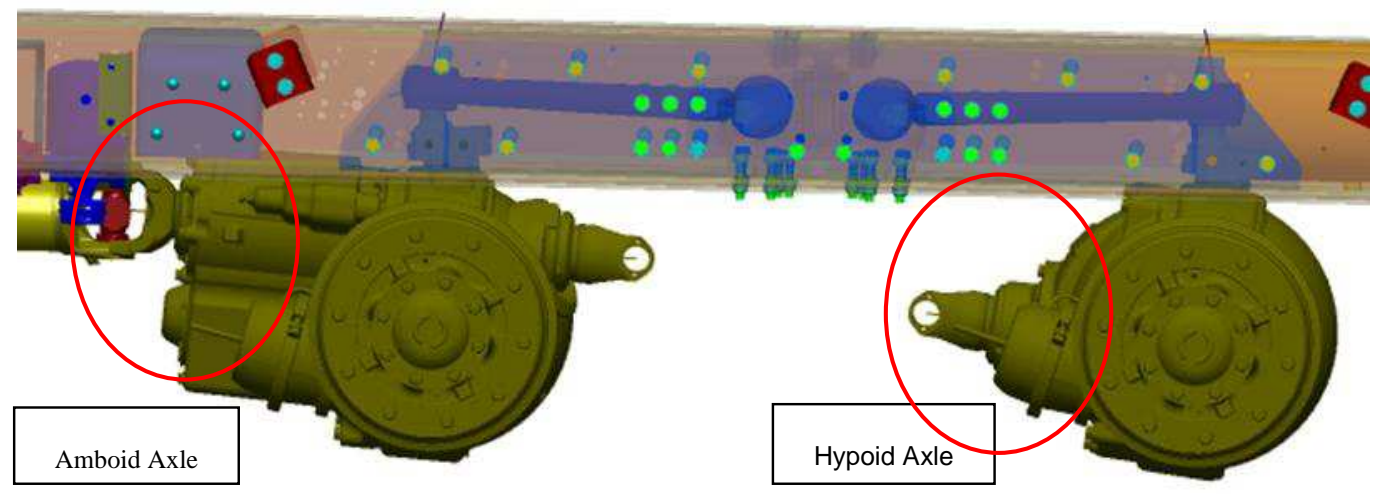

Picture 3. Visual difference between amboid and hypoid rear axles.

\section{PROJECT DESCRIPTION}

Evaluating the durability test vehicles we could confirm the judder vibration. The drive shaft layout configuration does not allow the angles best condition, according to supplier specification. Evaluating vehicles $6 \mathrm{X} 4$ we could verify that the first tractive axle have an amboid axle and the yoke is $180 \mathrm{~mm}$ higher than hypoid and have other yoke at rear axle position to assembly the tandem axle. The basic idea is remove the rear yoke and the gears and close the housing. It was done new layout and application sheet to be approved according to drive shaft maker requirements.
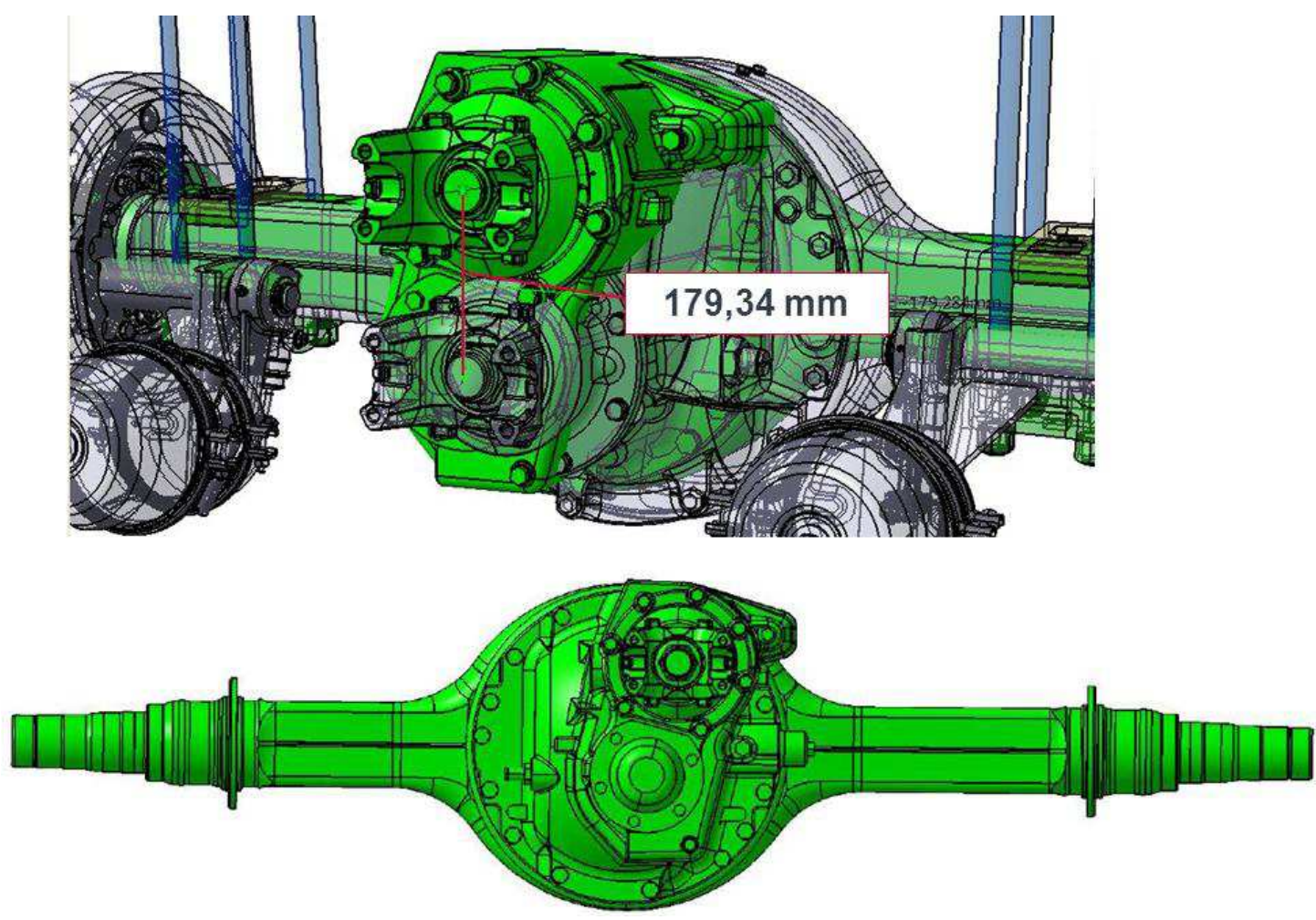

Picture 3. Amboid yoke center line 180mm higher than hypoid. 
The layout was evaluated individually and superimposed to confirm the differences regarding angles and suspension fixation.

\section{Current Compactor Layout}

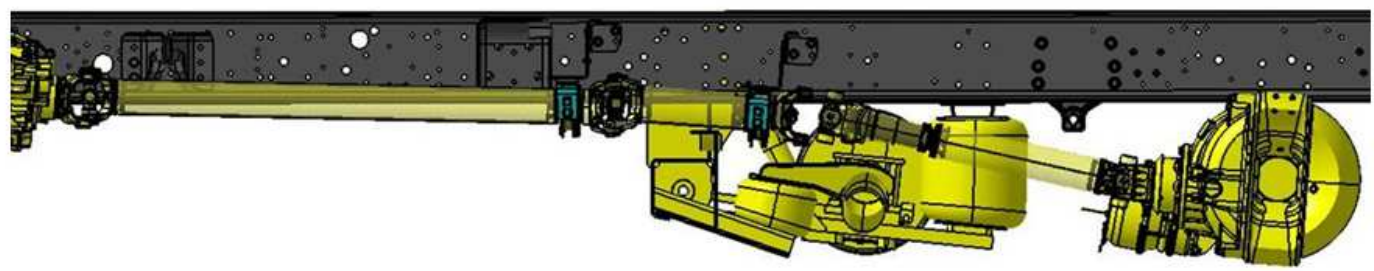

Layout With Amboid Rear Axle

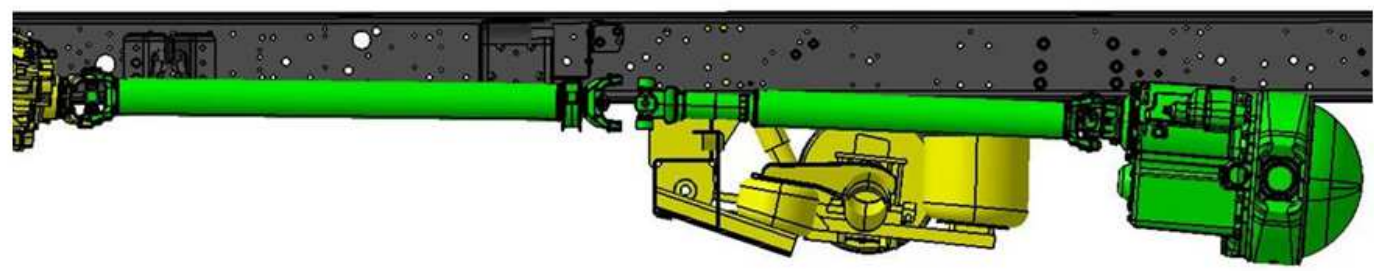

Picture 4. Layout differences
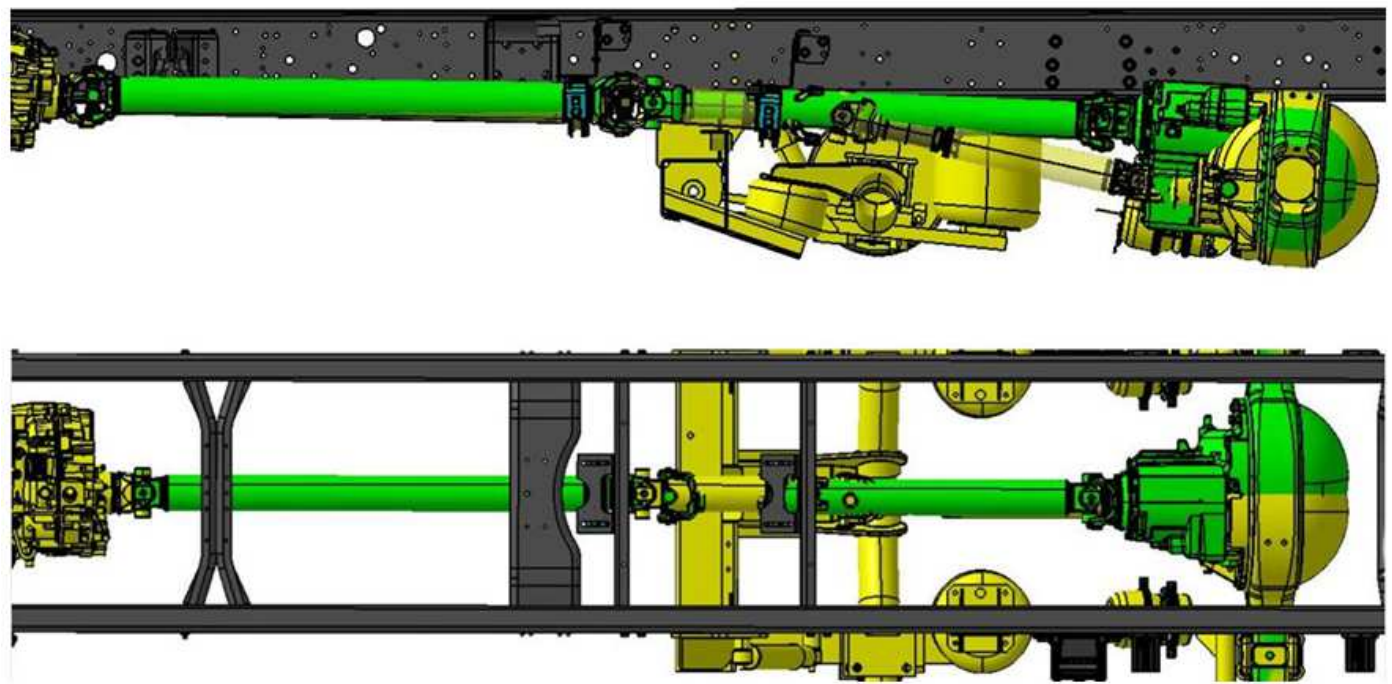

Picture 5. Layout superimposed

\section{LAYOUT ANALYSIS}

The layout analysis reduces the acceleration in drive and cost condition. According to the angles found it is not necessary to replace the original drive shaft mancal support to assembly the special mancal to absorb higher angles. It will be possible to assembly two drive shafts instead of three and eliminate one drive shaft support bracket. It is could represent a cost reduction at this vehicle.

Considering: 
- Maximum acceleration drive (inertial) $=800 \mathrm{rad} / \mathrm{sec}^{2}$

- Maximum acceleration coast (inertial) $=800 \mathrm{rad} / \mathrm{sec}^{2}$

- Maximum acceleration Torsional $=300 \mathrm{rad} / \mathrm{sec}^{2}$

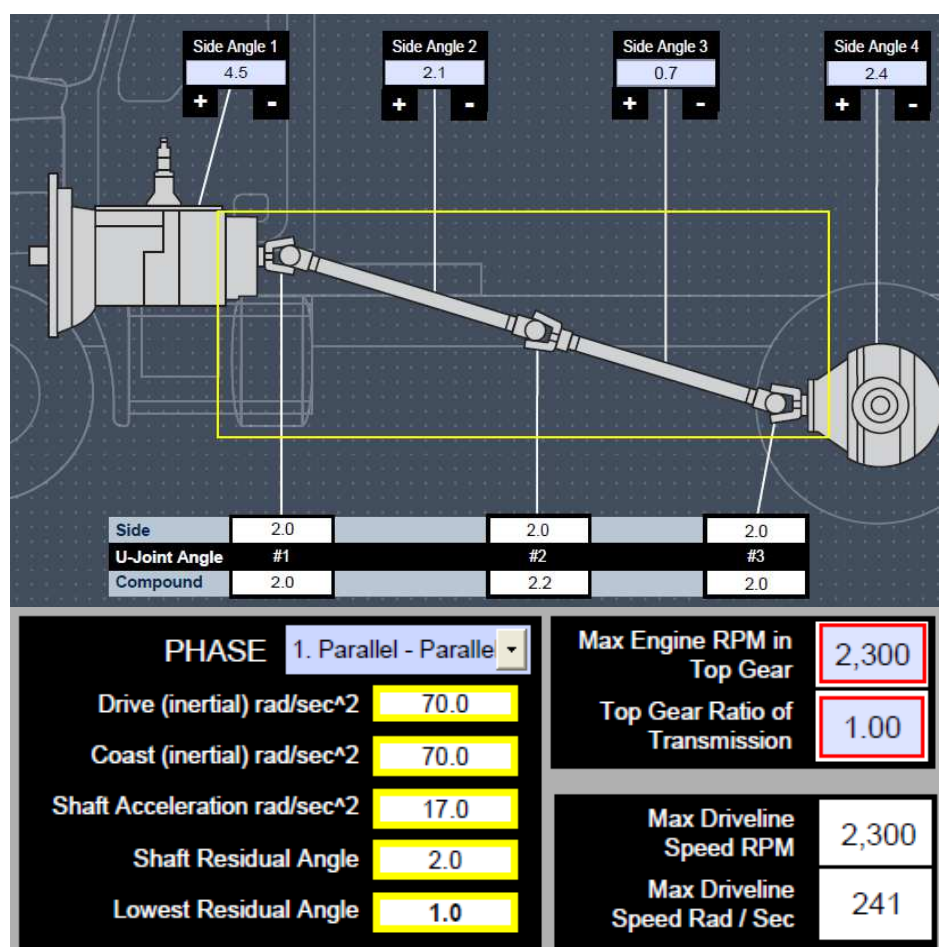

Picture 6. Universal joint angles and acceleration results for Amboid Axle (i.e. [1])

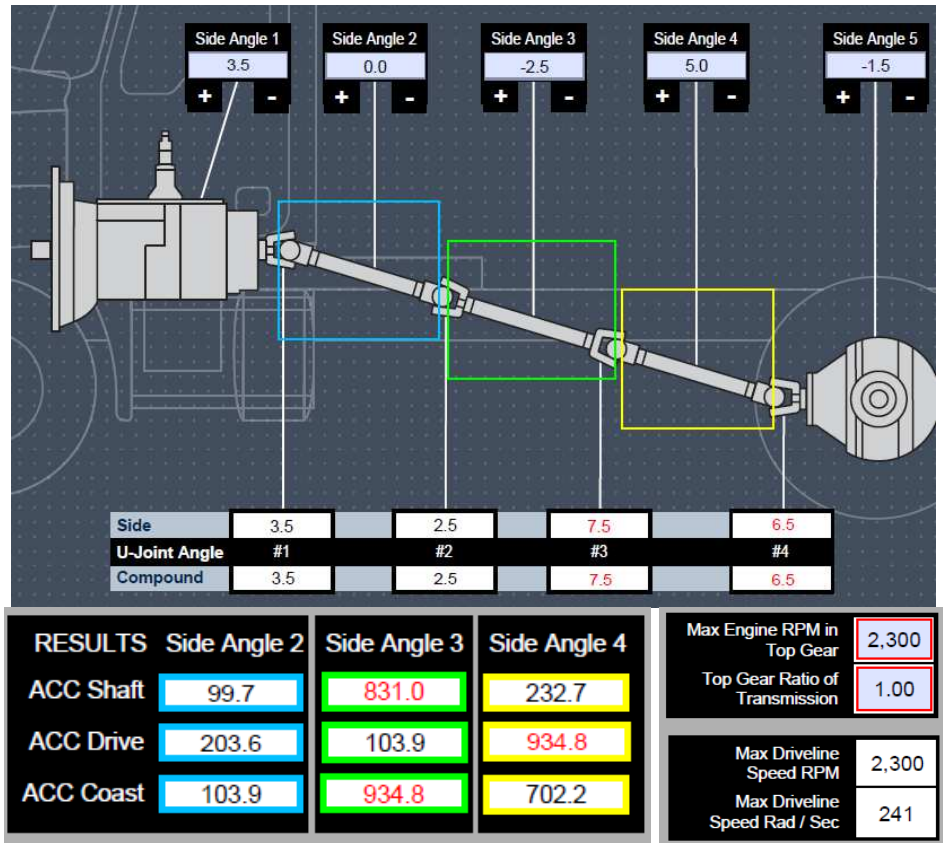

Picture 7. Universal joint angles and acceleration results for Hypoid Axle (i.e. [1]) 


\section{VEHICLE ANALYSIS}

It was assembled a compactor truck $6 \mathrm{X} 2$ with pusher system according to layout defined and tested in parallel at the current one in order to evaluate the judder vibration. We could confirm at uphill ramp $12 \%$ and $20 \%$ at $1^{\text {st }}$ gear between 1600 and $1800 \mathrm{rpm}$ during start/stop test no judder vibration at proposal vehicle and no vibration between 65 and $85 \mathrm{~km} / \mathrm{h}$ were found out as well.

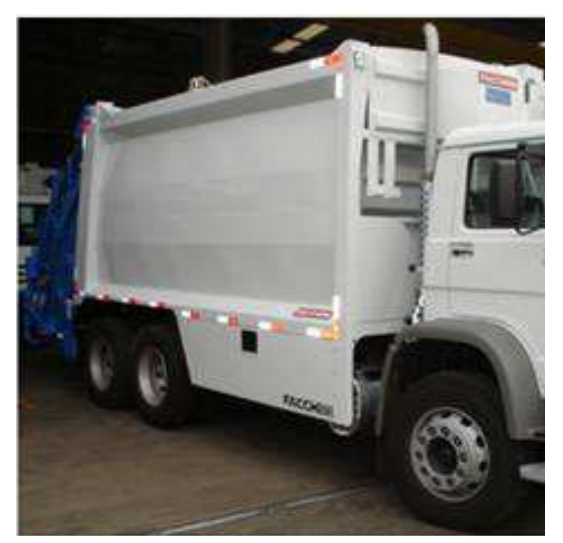

Picture 8. Vehicle assembled and evaluated.

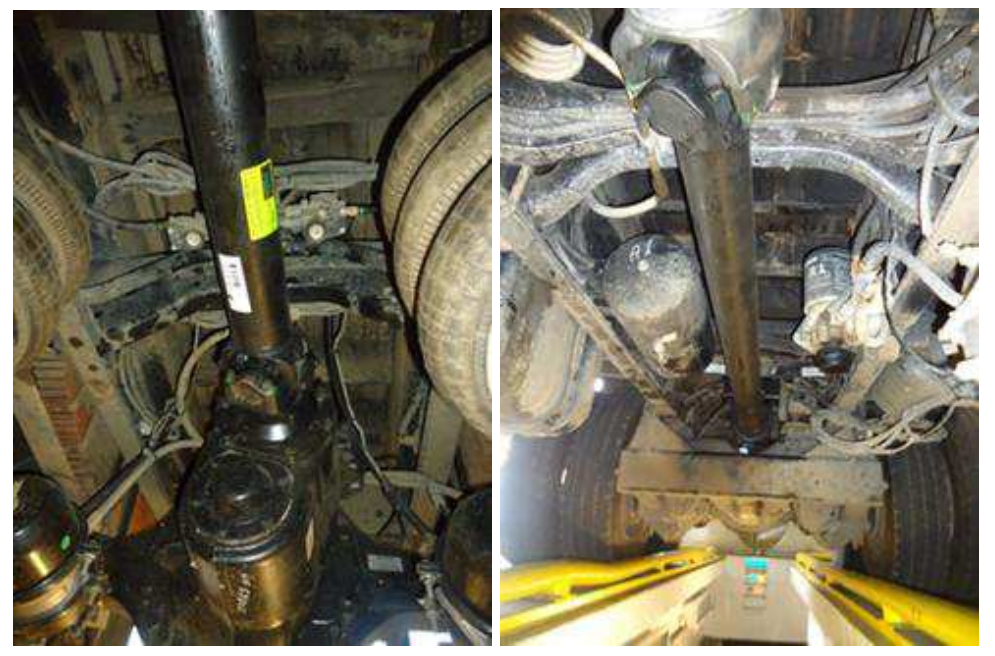

Picture 9 and 10. Amboid axle and drive shaft assembled.

\section{BENCHMARKING}

According to benchmarking done at refuse truck produced, we could verify that all 6X2 using a hypoid rear axle and pusher system.

\begin{tabular}{|c|c|c|c|c|c|}
\cline { 2 - 6 } \multicolumn{1}{c|}{} & OEM 1 & OEM 2 & OEM 3 & OEM 4 & OEM 5 \\
\hline Axle & Hypoid & Hypoid & Hypoid & Hypoid & Hypoid \\
\hline Model & MS 23 168 & MS 25 168 & MS 23 168 & R 780 & MS 23 168 \\
\hline
\end{tabular}

Table 1: Benchmarking at refuse trucks assembled. 


\section{CONCLUSIONS}

- The Patent for this idea was requested and the process is under conclusion.

- Evaluating the all cost involved to change the hypoid axle to amboid axle, we could confirm a cost reduction at this application.

- Judder vibration problem solved.

- High possibility to be leadership at this segment applying the amboid axle concept.

\section{REFERENCES}

[1] Drive Line Angle Analysis:

http://www.meritor.com/customer/northamerica/DriveLineAngleTool/Open.pdf

[2] Meritor do Brasil: Rear Axle Catalogue.

[3] H. CHR. SEHERR-THOSS, F. SCHMELZ, E. AUCKTOR, Universal Joints ad Driveshafts - Analysis, Desing ad Applications, Spriger Verlag, 2006

[4] DANA CORPORATION, Application Guidelines, DSAG0200, September 2007

[5] Internet Sites: www.volvotrucks.com.br; www.scania.com.br; www.iveco.com/brasil; www.fordcaminhoes.com.br; www.mercedes-benz.com.br . 